Annala, J. \& Mäkinen, M. (2016) Communities of practice in higher education: contradictory narratives of a university-wide curriculum reform. Studies in Higher Education (Published online: 12 Jan 2016). This is an Accepted Manuscript of an article published by Taylor \& Francis, available online: DOI:

10.1080/03075079.2015.1125877

\title{
Communities of Practice in Higher Education: Contradictory Narratives of a University-Wide Curriculum Reform
}

\author{
Johanna Annala and Marita Mäkinen
}

\begin{abstract}
This article presents an analysis of the experiences of scholars in a universitywide curriculum reform in one public research university. The focus is on the intentions and dynamics that shape the curriculum process in the local communities of practice. The data, comprised of interviews with twenty-five scholars, are examined as experience-centred narratives of curriculum change. Two distinct types of narrative-dialogical and reproductive-are found to reflect how the curriculum change was negotiated. In further analysis, Wenger's dimensions of communities of practice, namely, mutual engagement, joint enterprise and shared repertoire, are used as a conceptual framework to identify the intentions and dynamics behind the narratives. The following dimensions emerged: (1) intending to cross borders versus maintaining prevailing traditions and positions; (2) attempting to find shared goals versus delaying or discontinuing the process; and (3) having enough curiosity to familiarise oneself with the unfamiliar versus deprecating and rejecting it.
\end{abstract}

Keywords: higher education; curriculum as process; curriculum reform; community of practice; narrative analysis

\section{Introduction}

When a university-wide curriculum reform begins, the autonomous academic working cultures are shaken. Even if the university has endorsed the vision and strategic plan for reforming its degree programs, there is no university-wide means of ensuring that the 
faculties and academic communities will be engaged in the externally imposed curriculum renewal processes. This is due to the fact that, despite the curriculum being reified as an institutional document, its creation is inevitably preceded by negotiations of meaning (Wenger 1998) within the local academic communities. These negotiations of meaning often bring to light competing internal and external tensions regarding curricular missions, visions and individual scholars' prior beliefs.

The intentions and dynamics behind curriculum reform have been studied mainly from the institutional perspective and in varied national contexts (e.g. Blackmore and Kandiko 2012; Shay 2015). There are also studies focussing on individuals who have navigated curriculum change in specific faculty (e.g. Venance, LaDonna and Watling 2014), and others on the construction of academic identity during changes faced by the university in general (e.g. Clegg 2008; Ylijoki and Ursin 2013). However, there is a lacuna in research from the perspective of scholars who are attempting to understand university-wide curriculum changes in their own academic communities. In this study, the central idea is to deepen our understanding of the intentions and dynamics that shape the curriculum as process in local higher education communities of practice. Accordingly, this article presents an analysis of the experiences of scholars during a university-wide curriculum reform. The analysis addresses the following research questions:

(1) How was the university-wide curriculum reform negotiated in the higher education communities of practice?

(2) What kinds of intentions and dynamics can be identified in these negotiations?

\section{Curriculum as Process}

In this study, we understand curriculum as a process comprising iterative negotiations 
and action planning. A university-wide curriculum reform, as such a process, reflects underlying values, beliefs and principles related to learning, understanding, knowledge and disciplines, as well as interpretations of the purpose of higher education (Mäkinen and Annala 2010; see also Pinar et al. 1995; Barnett and Coate 2005). Moreover, discussions of curriculum reform reflect how the disciplinary curriculum cultures, including their relationship with the changing world and society, are interpreted and narrated.

In the context of higher education, fundamental ideas regarding curriculum are not always shared or knowingly negotiated (Coate 2009; Annala, Lindén and Mäkinen 2015). When the basic understanding of the objective of action is not shared, the main focus of relevant actions will vary. There may be different emphases, for example, in understanding curriculum as a product or process (e.g. Gleeson 2013) versus contentand learning-centred approaches to curriculum design and development (e.g. Roberts 2015). Also, there may be differences in how the university's task of educating for civilisation or employability is interpreted (e.g. Wang 2014).

Some approaches place knowledge at the centre of the conceptualisation of curriculum, such that 'curriculum defines what counts as valid knowledge' (Bernstein $1975,85)$. Other approaches stress that curriculum is more than a matter of knowledge or an encounter with knowledge itself. Instead, it is a multifaceted question of knowing, acting and being, i.e. the formation of epistemic dispositions and qualities (Barnett and Coate 2005; Barnett 2009). According to Barnett and Coate (2005), the domain of 'knowing' refers to the core knowledge of the discipline, 'acting' emphasises the skills and actions that students are expected to acquire, referring to how students' expertise grows and develops through activity, and 'being' denotes the formation of students' 
dispositions, qualities and identity. Together, these three domains characterise curriculum as a process, taking the students' perspective and agency into account.

Moreover, the process view, as represented by Pinar et al. (1995; Pinar 2004), highlights that curriculum is not knowledge for knowledge's sake, nor is it an institutionalised and bureaucratised thing. It is more than a process: 'it becomes a verb, an action, a social practice, a private meaning and a public hope' (Pinar et al. 1995, 848). The focal point is educating for understanding, as Pinar (2004) concludes:

understanding the relations among academic knowledge, the state of society, the processes of self-formation, and the character of the historical moment in which we live, in which others have lived, and in which our descendant will someday live. It is understanding that informs the ethical obligations to care for ourselves and our fellow human beings, that enables us to think and act with intelligence, sensitivity and courage in both the public sphere, as citizens aspiring to establish a democratic society, and in the private sphere, as individuals committed to other individuals (Pinar 2004, 187).

Some conceptualisations of curriculum include moral, political and global perspectives that underlie curriculum processes (e.g. Autio 2006; Vidovich, O’Donoghue, and Tight 2012). Curriculum may thus be framed by its internal and external premises that serve either the autonomous aims of the university and scholarship, or the requirements of working life and society (e.g. Clegg and Bradley 2006). Bernstein (1996, 68-69) used the concepts of 'introjection' and 'projection' to characterise this contradiction. 'Introjection' refers to the construction of curriculum on the basis of internal disciplinary interests, such that the curriculum takes shape according to the subject matter taught. 'Projection' describes curriculum change on the basis of external demands, such as the competence demands of the labour market. Either way, Bernstein reminds us that curricula constitute a set of choices and different forms of regulation. 


\section{Curriculum in Academic Communities of Practice}

As Pinar (2004) has suggested, curriculum as process can be seen as a 'complicated conversation' between different ideas and interest groups (185-187). Curriculum is reified as a textual document, but behind the text, manifold negotiations between scholars, administrative staff, students and stakeholders take place regarding what is valuable and inalienable, and what can be excluded. We suggest that this process can be described using Wenger's (1998) concept of 'negotiation of meaning', which entails both interpretation and action (52-55). According to Wenger, this happens through the interplay of two constituent processes, participation and reification. Participation refers to a process of taking part and engaging in relations with others involved in the process, but it is not tantamount to collaboration. Instead, 'it can involve all kinds of relations, conflictual as well as harmonious, intimate as well as political, competitive as well as cooperative' (56). Thus, participation in social communities has transformative potential not only in shaping people, but also in shaping communities, identities and ideas.

Wegner (1998) characterises reification as the variety of forms that congeal the experience into artefacts, like words, concepts, plans and design processes. Though reification and participation are distinct, they are complementary and interwoven. If one part of this duality is overly prevalent or lacking, the continuity of meaning may become problematic in practice. For example, without participation, a university strategy or curriculum ends up as a dead letter that is not put into practice, while without reification, there may be a great deal of participation and communication, but no material in which to 'anchor the specificities of coordination and to uncover diverging assumptions' (65). Therefore, both participation and reification are needed in the negotiation of meaning, because 'it is the interplay of participation and reification that makes people and things what they are' (70). 
Negotiations of meaning take place in local disciplinary communities, which are understood here as 'communities of practice' (CoPs). The CoP is a key feature in the social theory of learning developed by Wenger (1998; see also Lave and Wenger 1991), and the concept has been widely used in higher education research (Tight 2015). CoPs are informal or formal groups that are not necessarily well-defined or socially visible, but in which members know each other (Wenger 1998; Lave and Wenger 1991).

According to Wenger (1998), a CoP has three features: mutual engagement, a joint enterprise and a shared repertoire. In the context of this study, mutual engagement refers to the ways of and networks for communicating and responding to each other's actions regarding the curriculum process. A joint enterprise is about having a shared understanding of the objective of the actions, in this case, the objectives of the curriculum and the intentions underlying the curriculum reform. A shared repertoire is about the concepts, ideas, the ways and histories of doing things, and here, about sharing the traditions of and conceptions around curriculum. A community's shared repertoire is a joint resource for the negotiation of meaning, and it is dynamic and interactive by nature (Wenger 1998).

One scholar working at a university may belong to several CoPs, for example, a research group or network, a professoriate, the teachers of the same subject, scholars in the same degree programme or formal group like curriculum design team. Different CoPs may have different personal relevance, and that is why people engage in actions differently. In the context of this study, instead of assessing whether a curriculum design team or any other group of scholars has all of the characteristics of a CoP, we are interested in how the general features of CoPs emerge through narratives of curriculum change. 


\section{Research Context and Frames}

The present study is a part of a longitudinal curriculum research project at one multidisciplinary public research university ${ }^{1}$ in Finland (Figure 1). The project started in 2009. During that time, the university in question had forty departments and fifty-six undergraduate programmes - most often with subject-centred curricula - each of which had strong autonomy in curriculum development. In order to study the curriculum in higher education, each department was asked to name an interviewee from its curriculum development team, resulting in twenty-seven informants. The results of this first phase of the research project are reported elsewhere (Mäkinen and Annala 2010, 2012; Annala and Mäkinen 2011).

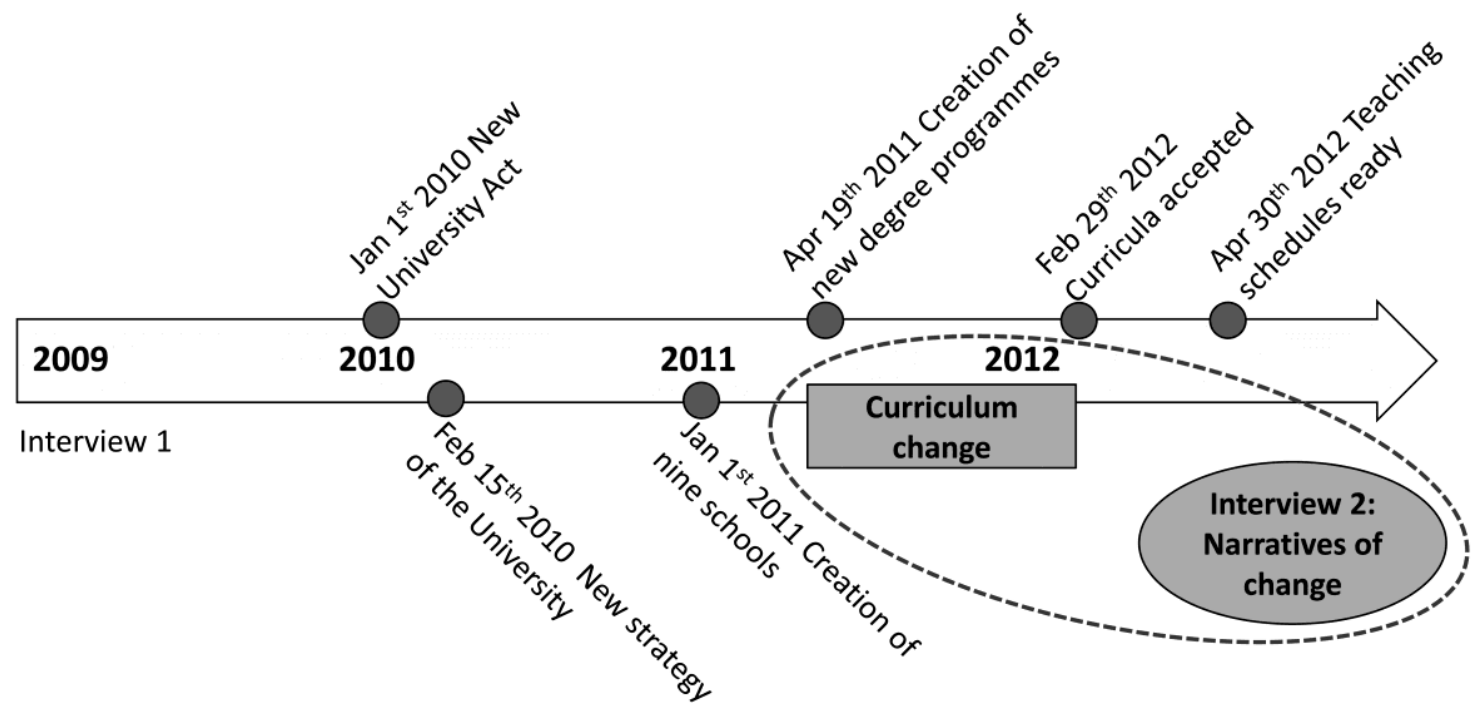

Figure 1. The research context

Between 2010 and 2012, the university in question launched a comprehensive educational and curriculum reform. Prior to it, the new University Act was confirmed in

\footnotetext{
${ }^{1}$ Some 15,000 students are currently pursuing degrees at the University. Every year, approximately 1200 Master's degrees and 140 doctoral degrees are produced. The personnel number at about 2,000. There are no tuition fees.
} 
Finland. It gave the public universities more freedom in decision-making and gave more responsibility for financing their activities and for defining their terms of operation and quality standards. Thus the reform was motivated by the strategy of this particular university, by 'shaping its own future', with the objectives of lightening the administrative structures and by that, providing the staff with improved opportunities for their core activities, and offering for the future applicants broad, strategically motivated study programmes that make impact on the society.

The forty departments were merged into nine disciplinary schools, and these schools took over all of the tasks of the former faculties and departments. The number of study programmes was reduced by half, and there was an organisational shift from subject-based education to broad degree programmes with curricula based on learning outcomes. Nine schools were founded in January 2011, and in April 2011, the new degree programmes were created. The curricula were to be ready after ten months, in February $2012 .^{2}$

The data for the present study were collected after the reform, between April and June 2012, comprised of twenty-five interviews. We reached seventeen of the informants interviewed previously (in 2009) and recruited eight more, again asking volunteers from the local curriculum teams to be interviewed, so that there was at least one interviewee from each of the new schools. The informants included twelve professors, seven senior lecturers, three university teachers and three administrative staff with teaching responsibilities, all of whom were involved in the process of curriculum change. In this study, we refer to all participants as 'scholars'3.

\footnotetext{
${ }^{2}$ In Finland, students are admitted to study the Bachelor and Master degrees at the same time; therefore, curricula were designed for both degrees during the change.

${ }^{3}$ In Finland, 'professor' means 'full professor'. Senior lecturers may be equivalent to assistant professors in some other countries. Some of the university teachers and administrative staff interviewed had doctoral degrees.
} 
The interviews had similar semi-structured themes as those carried out in 2009, concerning practices, processes, changes and the meanings of curriculum in general. The informants were encouraged to share their narratives of curriculum change rather freely from their own position or perspective. The interviews were audiotaped (duration 33-86 minutes, average 57 minutes) and transcribed verbatim.

\section{Ethical Considerations}

For ethical transparency, it is important to clarify our changing roles and positions during the research process. During the first interviews, in 2009, we were working as researchers in a research project at the university in question. During the reform in 2010-2012, we became involved in curriculum change in our own school as permanent scholars, as well as performing as experts at the university level by, for instance, giving lectures on curriculum in higher education. Our dual role, primarily as scholars and secondarily as experts involved in the change, was transparent to the leaders of the reform. The vice-rector of the university gave us permission to study the change from the standpoint that we, as researchers, considered significant.

In 2012, we did not collect the data personally because of our own involvement in the process. The interviewer was a person who did not participate in the reform. However, the informants were informed that the data were going to be analysed and studied by the authors and that the analysis would be undertaken with respect and ethical propriety, and that no single informant would be recognisable. Because of the selective recruitment, the department of origin was anonymised in the data, and this was explained to the interviewees. 
In all of the interviews, the informants were volunteers. Beyond the curriculum design process in the local community, many expressed a desire to talk about the reform in general. The interviewer explained that many participants took advantage of the interview to reflect upon and analyse the different phases they had gone through during the reform, and the interviews included a range of strong emotions, from happiness and success to frustration, anger and distress.

\section{Data Analysis}

The dataset, comprised of interviews with twenty-five scholars, was examined as a collection of experience-centred narratives (Bruner 1990) related to the transformation processes. These narratives are seen as a portal through which the experiences of the world of scholars are interpreted and made personally meaningful.

In the first phase, we applied Labov's (1982; Labov and Waletzky 2006) model of narrative structure for analysing the data. The original model includes six categories, but we drew on only two of them: complicating actions (the event, sequence or plot with a turning point) and resolution (the outcome of the plot). Accordingly, we sought complicating actions and resolutions (meaning units) in the interviewees' narratives, referring to turning points, challenges, shifts and their conclusions regarding curriculum change. This outline is considered suitable for uncovering the intentions and dynamics that shape curriculum change.

Next, we applied directed content analysis, introduced by Hsieh and Shannon (2005). Directed content analysis involves the application of conceptual categories to a new context, which is appropriate when existing theory or prior research about a phenomenon would benefit from further description. In this case, the nature of curriculum changed from subject-centred to broad degree programmes, and the context changed from autonomous to university-wide practices that required cooperation with 
others. Accordingly, the meaning units (complicating actions and resolutions) were reflected upon from within a comprehensive curriculum framework (Mäkinen and Annala 2010) and through Etienne Wenger's (1998) three-dimensional model of CoP.

A comprehensive curriculum framework (Figure 2) had been developed based on the first interview data from 2009 (Mäkinen and Annala 2010). The framework models the different meanings that are connected to curriculum in higher education, relying on the curricular aims of knowing, acting and being suggested by Barnett and Coate (2005), as well as on Bernstein's (1996) conceptions of 'introjection' and 'projection'. The comprehensive curriculum framework consists of nine complementary domains composed of two polarities - the most extreme forms of external or internal intentions. Between these polarities, there are interconnected views. This is where the starting point of curriculum arises, emerging from the internal idea of what a university education should be within a space that is likewise conscious of the external reality of the world around the university.

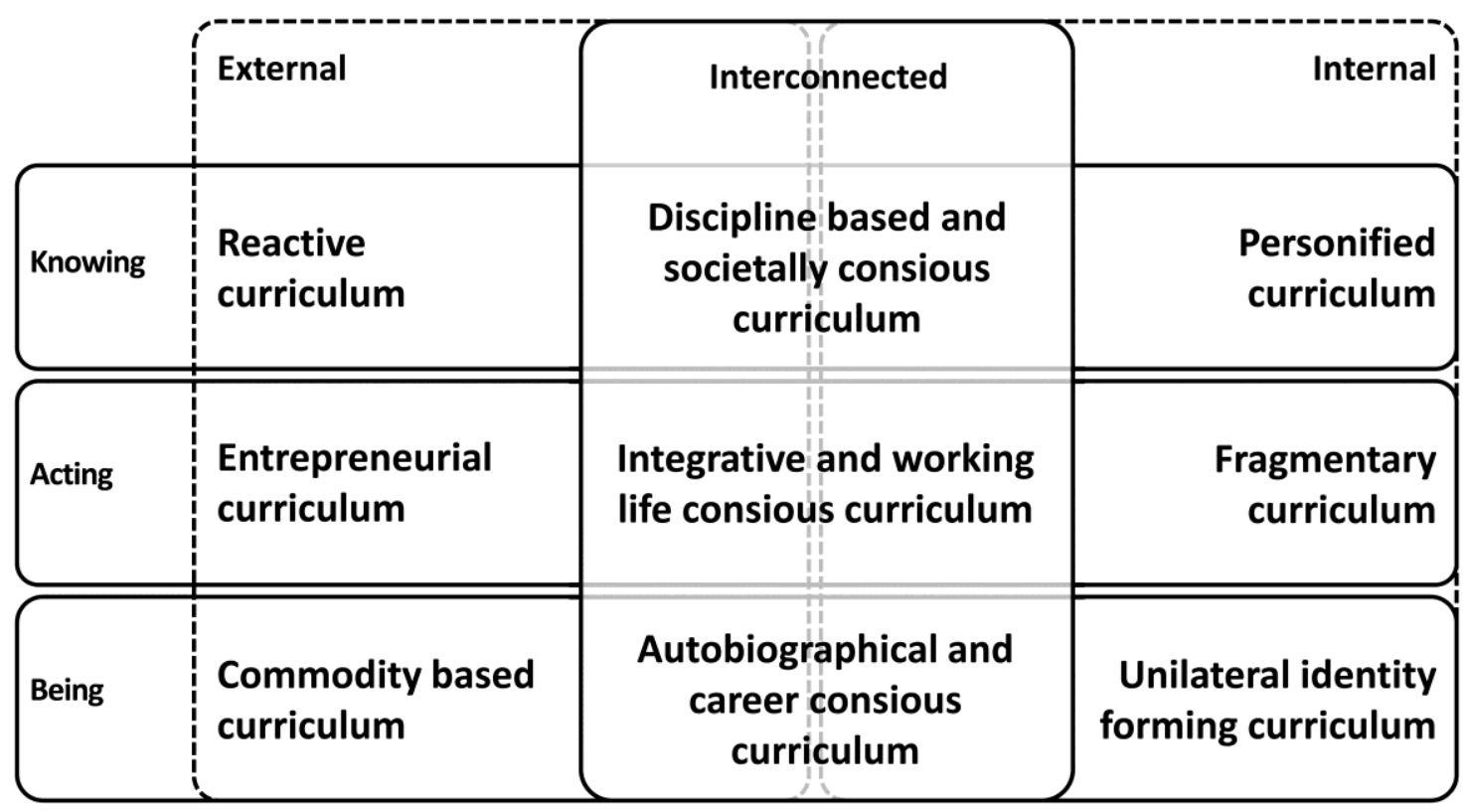

Figure 2. A comprehensive curriculum framework (Mäkinen and Annala 2010)

By examining the meaning units with the framework, an analysis of the most current 
data indicated that the external views regarding curriculum did not appear, as they had in the 2009 interviews. Instead, tensions were found between the internal views and the interconnected views on curriculum. In this context, the former are seen as representative of a 'reproductive narrative', while the latter represent a 'dialogical narrative'. It is important to note that, although the scholars described their own experiences of the curriculum change, they also had analytical notions regarding ways of acting as individuals and as CoPs. Therefore, a given interview was not necessarily categorised in its entirety as a dialogical or reproductive narrative; instead, each description of practices was categorised according to how practices were described, such that each interview may feature both kinds of perspective.

In order to identify the intentions and dynamics shaping these narratives of curriculum change, we used $\mathrm{CoP}$ as a sociocultural and heuristic device to highlight issues that had previously been overlooked (cf. Kimble 2006). We explored descriptions of joint enterprise, mutual engagement and shared repertoire within the narratives categorised as reproductive or dialogical. Finally, the findings were assessed by rechecking the meaning units and the quotes in the original context of the data.

In the following paragraphs, we describe the results. First, we introduce the reproductive and dialogical narratives that reflect how the curriculum change was negotiated. In the following section, we describe the results in more detail, with a particular focus on the kinds of intentions and dynamics that can be identified within these narratives. Each interview quote substantiating the findings is numbered and coded, indicating the participant's gender (male, M, or female, F).

\section{Narratives Reflecting the Curriculum Change}

Reproductive narratives reflect general resistance toward the curriculum reform. In particular, there was resistance to broadening the knowledge base, as exemplified in the 
following quote:

It hasn't gone the way I think it was supposed to go, so that it would be more broad-based. It hasn't gone that way. Only, it was written to look like it had. We don't want it to be broad-based; instead, we want to keep our own profile high. $(16 \mathrm{M})$

The speaker's desire here was to follow academic disciplinary and subject-based traditions; that is, he was concerned about how the content knowledge of a certain subject was to be maintained via courses in the curriculum. In reproductive narratives, the talk around curriculum reflected personal curriculum interests, fragmentary course collection and an interest in students' identity construction based on the subject's high profile (cf. Mäkinen and Annala 2010). The discussions about whose courses or specific books were included in the curriculum reflected highly personal curricular bias. What was seen as constituting core knowledge was an internal issue related to the person, subject or discipline. Other disciplines or schools within the university, current changes in society and students' possible career options after graduation did not appear to be resources for curriculum design. These were either absent or seen as a threat to the ideals of university education and autonomy. Nonetheless, scholars often built a façade to make it seem as if they were participating in the reform as expected, as revealed by the quote above.

Reproductive discourse highlights protecting one's 'own' from something from the 'outside'. This finding is consistent with Naidoo's (2005) and Lenartowicz's (2015) description of academics' inclination to protect their scientific field and interests against the outside world. Lenartowicz (2015) points out, referring to a theory of autopoietic (i.e. self-productive) systems, that 'they change only to be able to remain unchanged' (13). Also, Shay (2015) conceptualises curriculum reform as an 'arena of struggle' over the basis of legitimation. However, if there is no arena, or only minimal dialogue with 
'outsiders' within the university (e.g. other disciplines, subjects or schools), then the shared understanding of curriculum change will be created and adopted among the insiders. When the CoP has strong borders, cohesion seems to be strong and views likeminded. However, when there is communication and negotiation of meanings within the group, it can create fully unique interpretations of the notion of curriculum and the purposes of curriculum change.

In dialogical narrative, external threats are not ignored, but rather are understood as a resource for the staff. For example, through synergy in teaching in broad-based degree programmes, there could be more time for research. Here, the scholars interviewed took an active role in trying to understand the idea of curriculum and the intentions of the reform in dialogue with 'outsiders'. This called for a readiness both to cooperate with students, colleagues and the administration, and to take risks, which may lead to disappointment or to the discovery of something new. The following quote exemplifies dialogical discourse:

[...] it resulted in something new internally, that we actively built co-operation between and inside the university schools, more than before. It was especially these thematic, interdisciplinary study modules that led us to very constructive talks with disciplines that we hadn't been in much contact with or done anything together with before. Concrete things. The students have found connections before, but now we want to make it more regular and readily understandable for the students. (9M)

In this perspective, knowledge in curriculum was approached in a new way that, following Bernstein $(1975,80)$, can be seen as an integrated type of curriculum, which differs from the collection type, where contents are clearly bounded and separated from each other. While the discovery of interconnections between different courses and pieces of knowledge was previously left to students, these were now discussed among the scholars. They worked to determine, for example, how a certain phenomenon could 
be approached through the lens of a particular subject or disciplinary field, as is typically done in research collaboration. Similar kinds of border crossings had been noticed in working life and society, and so the change in curriculum was seen as reasonable. However, direct collaboration and considering the competency needs that arise from the requirements of working life were almost absent.

In sum, in contrast with the reproductive narratives, which reflected a view that the world outside was totally non-existent and that the university curriculum served only the internal interests of the university and of science, the dialogical narratives illustrated the scholars' desire to be conscious of the world outside and of working life, preferably being ahead of it rather than lagging behind. The external premises were more presumed than enquired after. Nevertheless, neither type of narrative followed the extreme external premise of curriculum change: the trend to design curriculum only in line with working life, economic and societal requirements (e.g. Edgren 2006; Hurlimann 2009).

\section{The CoP Triangle Revealing the Curricular Intentions and Dynamics}

The three intertwined dimensions of Wenger's (1998) concept of CoP, namely, mutual engagement, joint enterprise and shared repertoire, are reflected in the curricular narratives adopted by the interviewees. Taken as a whole, these dimensions revealed the following dominant intentions and dynamics: (1) intending to cross borders versus maintaining prevailing traditions and positions; (2) attempting to find shared goals versus delaying or discontinuing the process; and (3) having enough curiosity to familiarise oneself with the unfamiliar versus deprecating and rejecting it (Figure 2). 


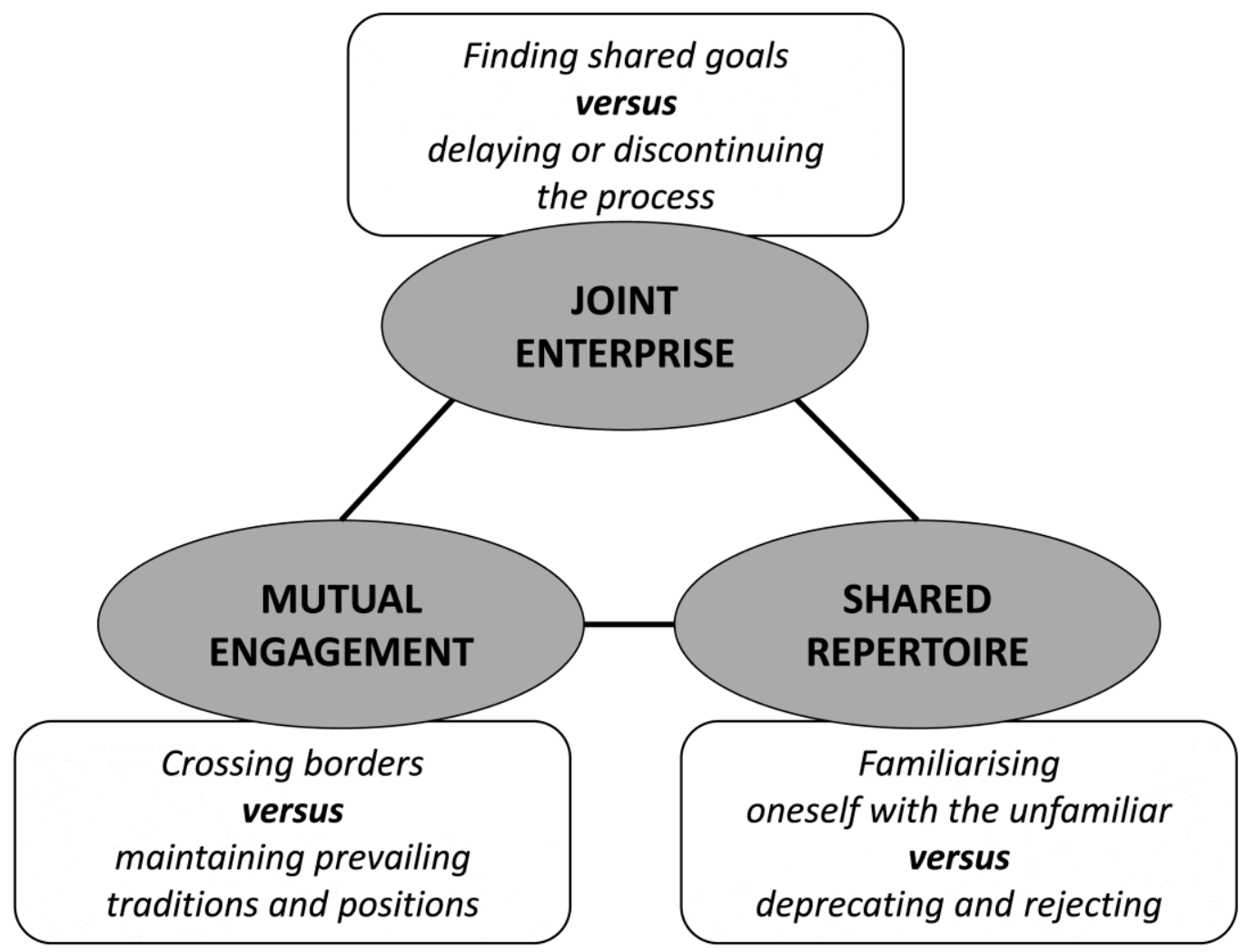

Figure 3. The curricular intentions and dynamics

\section{Mutual Engagement: Crossing Borders vs. Maintaining Traditions and Positions}

Professors have traditionally been responsible for the curriculum and degree requirements, generally with the help of the administration. In the present reform, all staff members, across disciplinary boundaries and posts, were encouraged to participate and contribute to transforming the subject-based curricula into broad-based degree programmes.

To create a new practice, mutual engagement is needed (Wenger 1998). In the current reform process, all staff members, including professors, teachers, researchers, doctoral students, undergraduate students and administrative staff, were involved in the curriculum design. As Wenger notes, practice implies a source of coherence within a community; it does not exist in the abstract, but emerges only when people are engaged 
in actions whose meanings they negotiate with each other (73). However, such mutual engagement was a challenge in the new organisational structure, where people did not exactly know their new colleagues or understand their role in the curriculum process. Given the prevailing academic culture, this kind of wide access was followed by confusion regarding who should engage and whose privilege or duty it was to participate in curriculum change, as illustrated by the following quote:

A: $[\ldots]$ next time there are some university-wide events about curriculum, only the chairpersons of different curriculum design teams should be invited, not administrative personnel. You know, categorically speaking. Those should be aimed at the curriculum team chairpersons.

Q: Was it for administrative personnel now?

A: Oh no, but you know, everybody was invited. But who was there, it was the administration. No professors from the curriculum design teams, the chairpersons. And for me, this sends quite a clear message, like this is not something that concerns us. Really, I think that everybody should participate. We are dealing with the content here. And it should be like a matter of honour for every curriculum chairperson. $(2 \mathrm{~F})$

One option was to withdraw from the formal process, and some scholars did so. Other scholars explained, as shown by the above quote, that the curriculum design team leaders and professors were supposed to engage only if access was limited. Accordingly, the wide access to curriculum change was seen as a threat to traditional disciplinary boundaries and prevailing positions with certain responsibilities. One interviewee asks: 'Are professors needed still at all?' (3M). This highlights the fact that CoPs are always linked to the power relations in the community (Jawitz 2007). In the present data, there were accounts of fringe groups of likeminded people who worked alongside the nominated curriculum teams. These CoPs were used to maintain the prevailing traditions and to sustain the reproductive curriculum culture. In some cases, in the end, these took the authority to 'steamroll' those who had less power. 
At the same time, in the dialogical narratives, there were experiences in which people collaborated more than ever before, despite the time pressure and tensions, and in which the scholars also noted that the participation and engagement of the whole staff had been helpful. Yet these were not experienced as a trouble-free processes, as exemplified in the following:

In a way, when people manage to get something done in spite of any conflicts there may have been, I think it is always a therapeutic and good experience, even if those who didn't achieve their personal goals don't feel happy about the outcome. (5M)

In the data, border crossings and new openings were described as worthwhile. When people managed to resolve conflicts and ended up with a compromise, it was an empowering experience. As discussed earlier, Wenger (1998, 75-77) noted that mutual engagement does not presume harmonious relationships. Mutual support and interpersonal allegiances may exist, but there also may be disagreements, tensions and conflicts. The key question is whether this kind of diversity was seen as a threat or as a resource within the prevailing CoPs.

In the dialogical narratives, diversity was regarded as productive and as a resource for complementary contribution. When new colleagues in the community showed enthusiasm, it inspired the other scholars. When a number of participants from different CoPs were involved in an encounter, the advantage was that the negotiations of meaning took place at the same time across boundaries and within each practice (cf. Wenger 1998, 112). Wenger (109) characterised this phenomenon as 'brokering', referring to the multi-membership of individuals who make connections across CoPs and through the translation, coordination and alignment of perspectives, which may open up new possibilities for meaning. However, almost everyone interviewed pointed 
out that there was too little time to interact, share and develop mutual engagement to approach curriculum change in the way that they had wanted.

\section{Joint Enterprise: Finding Shared Goals vs. Delaying or Discontinuing the}

\section{Process}

The endeavours of scholars varied in the social practices of curriculum change, and these were linked to diverse understandings of the purposes of the curriculum reform in general. According to Wenger (1998, 77-78), the negotiation of a joint enterprise keeps a $\mathrm{CoP}$ together, reflecting the complexity of mutual engagement. The joint enterprise is defined by the participants. It is not just a stated goal; it creates relations of mutual understanding regarding the practice. In this regard, the joint enterprise negotiated within the CoPs can align with or contradict the formal enterprise for curriculum change.

Even if they are critical of the change, in the dialogical narratives there was an attempt to find and follow shared enterprises. When novel ways of collaborating were supported or even forced due to the new university structures, it seemed to help the scholars to take an active role, not just in implementing the reform, but also in directing it in such a way that was meaningful and valuable for them, leaving them sufficient autonomy to explain the rationales behind the curricular decision making. For example, finding a connection between research and teaching was a shared enterprise that motivated curriculum change. Informants expressed that similar kinds of border crossings were already familiar in research groups, and it seemed natural to extend this into curriculum and teaching.

Another shared enterprise was to interpret the aim of the reform as a move from a teaching-centred curriculum design towards a learning-centred approach. In this case, a collection of the most valuable knowledge was not enough; they had to discuss how to 
support students' processes of coming to know and how to prepare them for an unknown future. Following Barnett and Coate (2005), the curriculum change can be seen as a question of ontological engagement meant to educate students for active citizenship in a world of uncertainty. Some scholars followed this kind of intention in the curriculum change, understanding that curriculum is about the growth of students' academic expertise, while remaining aware of the idea of a university education and its role in the changing society (cf. Annala, Lindén and Mäkinen 2015).

However, when there was a lack of understanding of the enterprise at the university and school levels, both between different CoPs and individuals, some scholars felt disappointed, particularly if there were no thought-provoking negotiations of the purposes and practices of curriculum, as shown in the following quote:

[...] we had this fine theoretical knowledge and a vision, a concept, the idea of what we were trying to do. So that one doesn't just go right ahead to the implementation, and start talking about courses one wants to get rid of, or how the basic courses should be changed; instead, first we should have had this phase with absolutely no comments allowed regarding any of the courses. We should have talked about what this or that means, what are the premises we can commit ourselves to. $(1 \mathrm{~F})$

In the reproductive narratives, the understanding of the scope of curriculum change ranged from the practical and personal details to the policy level, but the topic of curriculum as a negotiated process was absent. The narratives reflected joint enterprises to resist, delay or discontinue the curriculum change in general. In this respect, the energy in the shared enterprises was aimed against, not toward something. The resistance was explained through criticism of an increasingly managerial university that followed neoliberal values that served primarily political or economic purposes. As such, the larger historical and institutional context were present in the CoPs. The 
justification for the curriculum change was explained, for example, as a managerial attempt to reduce the professors' power or an intention to transform the university into something more like a school. At the same time, the criticism focussed on very practical issues, like resisting the suggestion that the study modules should not be smaller than five credits. Personal anxiety, prejudice and disinterest in the curriculum change seemed to be interwoven into the perceptions.

When the focus is on certain matters and others are left aside, and when some actions or perspectives are regarded as important and others ignored, the CoP is negotiating and constructing a shared enterprise. Notions regarding the selective course of action created tensions, and a new kind of pedagogical leadership was called for. However, the question of leadership in curriculum change and CoPs was complex (cf. Wenger and Snyder 2000; Wenger, McDermott and Snyder 2002). First, when CoPs are informal and organic, the leadership and power relations can be hidden, and it may be difficult to interfere. Second, as the university is an organisation with highly qualified experts, the leadership and the role of curriculum teams can be formal, but have no mandate in practice. In these data, these notions were linked to the concern that, after the formal artefact of curriculum was produced, the negotiations of meaning and mutual engagement in the shared enterprise would not continue when the curriculum change reached the implementation phase.

\section{Shared Repertoire: Familiarising Oneself with the Unfamiliar vs. Deprecating and Rejecting}

In the new organisational structures, several subject-based repertoires - routines, stories, concepts, words, symbols, beliefs, tools and ways of doing things - were encountered through other disciplines. The repertoires the communities had adopted during their history also came across in the new repertoire introduced by the reform. The new 
repertoire, as a set of artefacts or boundary objects (cf. Wenger 1998, 105), did not guarantee new practices of use or the organisation of the interconnections between various CoPs. The narratives featured devaluation and rejection, as well as curiosity and willingness to familiarise oneself with the unfamiliar.

Regarding the ways of doing things, there was no history of or routine for implementing a university-wide curriculum change that required dialogue and cooperation. The new repertoire was approached with inconsistent expectations. If there was room to negotiate and create one's own interpretations, the lack of set guidelines provoked complaints. If there were guidelines, these were criticised as a managerialist attempt to restrict autonomy. Besides, many tools, like the newly created intranet, where information was delivered, and the data system where curriculum was entered, were not familiar.

Moreover, some words, like 'learning-outcomes', were new. Instead of saying what the degree requirements were, which courses they were going to teach and which books would be included, the scholars were required to describe what students were expected to learn. For some, this was an unfamiliar perspective; perhaps it was so new that it was easier to reject it and claim that it was just some administrative or pedagogical language. Interviewees talked about how the 'verb-lists' and 'learningoutcome language' caused amusement. One scholar captured this dilemma with the following reflection:

[...] some people talked about how we should only use a lot of verbs, you know, they kind of talked down what the whole thing really should be about, but I still can't quite figure it out myself. Either it is such a big linguistic or mental twist that it just takes time to understand it, or then again, maybe I was just too exhausted to understand anything. (23F)

The repertoire introduced during the reform was difficult to understand and adopt if 
people had not participated in the lectures or meetings where these issues had been negotiated and linked to theories or some wider understanding. Also, written guidelines were read with distortion. For example, a guideline that encouraged scholars to pay attention to sustainable development in all curricula generated the following interpretation: 'we don't have to teach recycling of waste as a part of our courses; I think that is somewhat ridiculous' $(25 \mathrm{~F})$.

Several scholars pointed out that people had adopted many beliefs and assumptions without developing an informed understanding. One interviewee explained that she had read more than twenty papers by a new colleague in order to be able discuss their shared curriculum domain. The new colleague responded with misconceptions and faulty information regarding her disciplinary area. This caused frustration and disappointment. Moreover, this was confusing when it involved scholars, who are supposed to have an analytical mind-set in their consideration of knowledge and truth. This obvious approach to research did not transfer into academic curriculum practices. Instead, disparagement and refraining from cooperative actions seemed to be a powerful way to exercise influence on curriculum change.

The history of subjects or disciplines was even described as hostile, often 'because these are alike but still distinct' (14M). Hostilities emerged during curriculum change, but fundamentally, it was not a question of curricular issues. Before, the logics for gaining status in higher education involved differentiation, but now scholars were expected to find commonalities and develop a cooperative repertoire. According to the narratives, it seemed that it was easier to cooperate with someone from a distance. Indeed, as Wenger $(1998,130)$ has noted, proximity does not always work. If two disciplines were physically or thematically far enough away from each other, the scholars might be curious enough to get to know each other. Either way, the curriculum 
change revealed the prevailing cultures of learning and doing things and, furthermore, made the stories rooted in history visible.

\section{Discussion}

In the present study, we have explored curriculum as a process in the context of a university-wide curriculum reform. We were interested in how the curriculum change was negotiated in the higher education CoPs and what kinds of intentions and dynamics could be identified in these negotiations. The study showed that curriculum change is a highly complex social process, which is related to the individual, disciplinary and institutional identities and reflects the power relations within the academy.

The results reveal that a critical approach toward the continuous reforms facing universities was present in both reproductive and dialogical narratives. On the basis of the results, we suggest, in line with Wenger $(1998,80)$ that the curriculum reform as an enterprise was not fully determined by an outside mandate; instead, the practice evolved into the community's own, more or less active or passive, response to that mandate. It was the community that negotiated the meanings at all levels - including the university, degree programmes and scholar teams - and made decisions in accordance with members' positions, understandings and interests. The negotiation of meaning included an understanding of the concept of curriculum in general, and it materialised in different contexts. Within the context of local disciplinary communities, it made the curriculum design what it is, and eventually, in the context of the whole university, it made the curriculum reform what it is.

When reflecting upon the narratives through Wenger's theory, several questions arose, such as whether the scholars were engaged in actions at all, or whether they were willing to negotiate meanings across traditional boundaries. According to Wenger (1998, 167), through the participation and non-participation people define their 
identities and simultaneously use their power as individuals and as communities. Lenartowicz (2015) has noted that resistance to change should not be regarded as only an individual or psychological phenomenon, but rather as systemic and social. The university's social system is based on meanings that are self-produced and reproduced through processes of communication and interaction (Lenartowicz 2015). If the communication and interaction is limited to certain social systems, it is hard to reach a shared meaning of curriculum change and its purposes. This is consistent with McGrath and Bolander Laksov's (2014) argument that there is a risk of communicative mismatch and crosstalk in institution-wide educational reforms.

Research universities are comprised of split and fragmented communities (e.g. Brew 2010), as illustrated in the present study, and these communities are challenged by simultaneous changes. When organisational changes occurred some months before the curricular changes, the repertoire was transformed, and scholars were often unable or unwilling to find new forums for negotiation of the shared enterprise in curricular change or to reach mutual engagement in work practices. The narratives reflect committed enterprises that were linked to the disparate values and aims of the scholars' actions. If the ideals were not achieved, many felt that they had failed. Yet these different perspectives regarding curriculum change could be used as a productive tool in finding novel approaches to the collective identification of the core nature and purpose of higher education today.

We suggest that these results have the following implications. In order to have broad-based degree programmes that are scientifically and pedagogically reasonable, curriculum change requires dialogue across many borders. If there is no shared understanding of the purposes of curriculum, the object of the actions will focus on separate goals and create tensions among individuals and CoPs. There is a need for 
creating spaces for the negotiation of the fundamental premises where members of the academic community can mutually engage. Curriculum change calls for curriculum leadership at all levels of reform, and, at the same time, it requires the members of the academic community to be able and willing to create connections. This may happen through 'brokering', such as encouraging multi-membership in different CoPs, and through the creation of 'boundary objects' by sharing artefacts to create interconnections between CoPs (cf. Wenger 1998, 89).

However, participation in the negotiations of meaning goes beyond mere engagement in practice; as Wenger (1998) states, 'it is constituent of our identities' (57). Moving from subject-based curriculum to broad degree programmes shook the foundation of the university education, supporting Lenartowicz's (2015) point that the university, as an institution, has a very strong organisational identity. In this study, we did not explore the disciplinary identities, even though stronger or weaker boundaries emerged when the curriculum change was negotiated. In this respect, further studies are needed. Also, the curriculum culture's relation to academic working cultures and power relations needs more attention. In particular, future studies should be directed toward the CoPs themselves, exploring what kinds of CoP fundamentally direct the approach to curricular changes and decision making in higher education.

\section{References}

Annala, J., and M. Mäkinen. 2011. "Research-Teaching Nexus in Higher Education in Curriculum Design.” Transnational Curriculum Inquiry 8 (1): 3-25.

Annala, J., J. Lindén, and M. Mäkinen. 2016. ”Curriculum in Higher Education Research.” In Researching Higher Education. International Perspectives on Theory, Policy and Practice, edited by J. Case, and J. Huisman, 171-89. London, UK: Routledge \& SRHE. 
Autio, T. 2006. Subjectivity, Curriculum and Society. Between and Beyond the German Didaktik and Anglo-American Curriculum Studies. London: Lawrence Erlbaum Associated.

Barnett, R. 2009. "Knowing and Becoming in the Higher Education Curriculum." Studies in Higher Education 34 (4): 429-40.

Barnett, R., and K. Coate. 2005. Engaging the Curriculum in Higher Education. Berkshire, GBR: McGraw-Hill Education.

Bernstein, B. 1975. Class, Codes and Control. Volume 3. Towards a Theory of Educational Transmissions. London: Routledge \& Kegan Paul.

Bernstein, B. 1996. Pedagogy, Symbolic Control and Identity. Theory, Research, Critique. London: Taylor \& Francis.

Blackmore, P., and C.B. Kandiko. 2012. Strategic Curriculum Change. Global trends in Universities. London: Routledge.

Brew, A. 2010. "Imperatives and Challenges in Integrating Teaching and Research." Higher Education Research and Development 29 (2): 139-50.

Bruner, J. 1990. Acts of Meaning. Cambridge, MA: Harvard University Press.

Clegg, S. 2008. “Academic Identities under Threat?” British Education Research Journal 34 (3): 329-45.

Clegg, S., and S. Bradley. 2006. "Models of Personal Development Planning: Practice and Processes.” British Educational Research Journal 32 (1): 57-76.

Coate, K. 2009. “Curriculum.” In The Routledge International Handbook of Higher Education, edited by M. Tight, K.H. Mok, J. Huisman, and C.C. Morphew, 77-90. New York: Routledge. 
Edgren, G. 2006. "Developing a Competence-Based Core Curriculum in Biomedical Laboratory Science: A Delphi Study.” Medical Teacher 28 (5): 409-17.

Gleeson, J. 2013. "The European Credit Transfer System and Curriculum Design: Product before Process?" Studies in Higher Education 38 (6): 921-38.

Hsieh, H.F., and S.E. Shannon. 2005. "Three Approaches to Qualitative Content Analysis." Qualitative Health Research 15 (9): 1277-88.

Hurlimann, A.C. 2009. "Responding to Environmental Challenges: An Initial Assessment of HE Curricula Needs by Australian Planning Professionals.” Environmental Education Research 15 (6): 643-59.

Jawitz, J. 2007. "New Academics Negotiating Communities of Practice: Learning to Swim with the Big Fish.” Teaching in Higher Education 12 (2): 185-97.

Kimble, C. 2006. “Communities of Practice: Never Knowlingy Undersold.” In Innovative Approaches for Learning and Knowledge Sharing, edited by E. Tomadaki, and P. Scott, 218-34. EC-TEL Conference Workshops Proceedings.

Labov, W. 1972. Language in the Inner City: Studies in the Black English Vernacular. Philadelphia: University of Pennsylvania Press.

Labov, W., and J. Waletzky. 2006. "Narrative Analysis: Oral Versions of Personal Experience.” In Narrative Methods. Volume I. Narrative Perspectives, edited by P. Atkinson, and S. Delamont, 1-40. London: Sage.

Lave, J., and E. Wenger. 1991. Situated Learning. Legitimate Peripheral Participation. Cambridge, US: Cambridge University Press.

Lenartowicz, M. 2015. “The Nature of the University.” Higher Education 69 (6): 94761. doi:10.1007/s10734-014-9815-0 
McGrath, C., and K. Bolander Laksov. 2014. "Laying Bare Educational Crosstalk: A Study of Discursive Repertoires in the Wake of Educational Reform." International Journal of Educational Development 19 (2): 139-49.

Mäkinen, M. and J. Annala. 2010. "Meanings Behind Curriculum Development in Higher Education.” PRIME 4 (2): 9-24.

http://tampub.uta.fi/M/meanings_behind_curriculum_2010.pdf.

Mäkinen, M. and J. Annala. 2012. "Understanding Curriculum in Finnish Higher Education." In Higher Education Research in Finland - Emerging Structures and Contemporary Issues, edited by S. Ahola and D. M. Hoffmann, 219-312. CHERIF: Yearbook of Higher Education Research. Jyväskylä: Institute for Educational Research.

Naidoo, R. 2005 "Universities in the Marketplace: The Distortion of Teaching and Research.” In Reshaping the University: New Relationships Between Research, Scholarship and Teaching, edited by R. Barnett, 27-36. Berkshire, GBR: McGraw-Hill Education.

Pinar, W.F. 2004. What is Curriculum Theory? Mahwah, New Jersey: Lawrence Erlbaum Associated.

Pinar, W.F., W.M. Reynolds, P. Slattery, and P.M. Taubman. 1995. Understanding Curriculum. An Introduction to the Study of Historical and Contemporary Curriculum Discourses. New York: Peter Lang Publishing.

Roberts, P. 2015. "Higher Education Curriculum Orientations and the Implications for Institutional Curriculum Change." Teaching in Higher Education 20 (5): 542-55.

Shay, S. 2015. "Curriculum Reform in Higher Education: A Contested Space.” Teaching in Higher Education 20 (4): 431-41.

Tight, M. 2015. "Theory Application in Higher Education Research: The Case of Communities of Practice.” European Journal of Higher Education 5 (2): 111-26. doi:10.1080/21568235.2014.997266 
Venance, S. L., K. A. LaDonna, and C.J. Watling. 2014. "Exploring Frontline Faculty Experiences After a Curriculum Change.” Medical Education 48: 998-1007. doi:10.1111/medu.12529

Vidovich, L., T. O'Donoghue, and M. Tight. 2012. “Transforming University Curriculum Policies in a Global Knowledge Era: Mapping a "Global Case Study" Research Agenda." Educational Studies 38 (3): 283-95.

Wang, C-L. 2015. "Mapping or Tracing? Rethinking Curriculum Mapping in Higher Education.” Studies in Higher Education 40 (9). doi: 10.1080/03075079.2014.899343

Wenger, E. 1998. Communities of Practice. Learning, Meaning and Identity. Cambridge: Cambridge University Press.

Wenger, E., R. A. McDermott, and W. Snyder. 2002. Cultivating Communities of Practice: A Guide to Managing Knowledge. Boston: Harward Business School Press.

Wenger, E., and W. M. Snyder. 2000. "Communities of Practice: The Organizational Frontier." Harward Business Review Jan-Feb: 139-45.

Ylijoki, O., and J. Ursin. 2013. "The Construction of Academic Identity in the Changes of Finnish Higher Education." Studies in Higher Education 38 (8): 1135-49. 